\title{
Computing the relative land subsidence at Venice, Italy, over the last fifty years
}

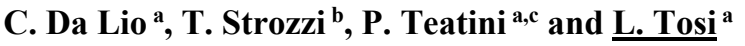 \\ ${ }^{a}$ Institute of Marine Sciences - National Research Council (ISMAR-CNR), Venice, Italy \\ ${ }^{b}$ GAMMA REMOTE SENSING AG, Gümligen, Switzerland \\ ${ }^{c}$ Department of Civil, Environmental and Architectural Engineering, University of Padova, Padova, Italy \\ Email:1uigi.tosi@ismar.cnr.it
}

\begin{abstract}
Land subsidence causes various damages to the infrastructures and cultural heritage in many cities worldwide. Urban flooding is one of the main consequences of land subsidence in coastal cities, where it is exacerbated by sea-level rise accompanying global climate change, but also in inland metropolitan areas such as Mexico City, where subsidence zones are increasingly flooded following intense rainstorms.
\end{abstract}

The subsidence of Venice, one of the most beautiful and famous cities in the world, is well known not for the magnitude of subsidence but because subsidence has seriously compromised the heritage and the safety of the city in relation to its small elevation above the sea. The storm that flooded the historical center of Venice on November 4, 1966 dramatically revealed its fragility with respect to land subsidence and sea-level rise, or the Relative Land Subsidence (RLS), i.e. land movement with respect to sea-level changes. That event signaled the beginning of a systematic monitoring of the loss in elevation of the ground surface of Venice with respect to the mean level of the Northern Adriatic (NA) Sea. Tide gauge measurements, available from the beginning of the last century, have been supplied historically by levelling and more recently by Synthetic Aperture Radar (SAR)-based Interferometry.

On the occasion of the $50^{\text {th }}$ anniversary of the 1966 flood event, we quantify the RLS experienced by the city over these last five decades with a detail never achieved before. The computation of the loss of elevation has been obtained by processing and superposing the results of levelling surveys carried out in 1961, 1969, 1973, and 1993, together with the results of Interferometric processing of SAR images acquired from satellites: 1993 to 2002 by ERS-1/2, 2003 and 2010 by ENVISAT, 2008 to 2013 by TerraSAR-X, and 2012 to 2016 by COSMO-SkyMED. The records from the tide gauge in Trieste, which is a city on the coast of the NA Sea close to the Alps and known to be stable, are used to evaluate the sea-level rise over the targeted time interval.

The mean land velocity $(v)$ for each analyzed period has been obtained by interpolating the original measurements using the Kriging method on a same regular 50-m grid covering the entire city. Then, cumulative land subsidence $\left(L S_{\text {tot }}\right)$ from 1966 to 2016 has been simulated in a GIS environment by summing the partial land subsidence over the various periods covered by the levelling and SAR surveys.

The results point out that in the Venice historical center between 1966 and 2016:

- Land subsidence rate has been more variable in space but less variable over time than the changes of the NA mean sea level;

- average subsidence has amounted to $0.8 \mathrm{~mm} / \mathrm{yr}$ and the average NA msl rise to $1.9 \mathrm{~mm} / \mathrm{yr}$;

- minimum and maximum cumulative subsidence has totalled $8 \mathrm{~mm}$ and $93 \mathrm{~mm}$, respectively; and

- maximum loss of elevation with respect to the NA msl (i.e. RLS) has been $190 \mathrm{~mm}$.

RLS has produced a tangible effect on the Venice historical center revealed by the continuous increase in frequency of the flooding events, locally called "acqua alta". In the next years, any further loss of elevation with respect to the mean sea level, even a few $\mathrm{mm}$, will threaten the city's survival with severe social and environmental impacts. Considering the present average land subsidence of Venice and sea level rise of the NA (i.e. both about $1.2 \mathrm{~mm} / \mathrm{yr}$ ), an additional loss of elevation of about $190 \mathrm{~mm}$ will likely occur by 2100 . Actually, according to conservative and pessimistic IPCC scenarios, the sea-level accompanying global climate change is expected to rise from 32 to $56 \mathrm{~cm}$. Therefore, the outcomes from this study should be properly taken in account for the planning of effective interventions for the mitigation of climate changes to maintain the historical center of this unique city.

Keywords: Coastal subsidence, sea level rise, Venice historical center 


\section{INTRODUCTION}

Land subsidence is the lowering of the ground surface due to natural and man-induced processes occurring in the shallow and deep subsoil. Natural and anthropogenic factors act on different timescales, i.e. millions to thousands years for the former and hundreds to a few years for the latter, reflecting the geological history and the human development in the territory.

Land subsidence causes various damages to the infrastructures and cultural heritage in many worldwide cities. Urban flooding is one of the main consequences of land subsidence in coastal cities such as Jakarta (Ng et al., 2012), Indonesia, where it is exacerbated by sea-level rise accompanying global climate change, but also in inland metropolitan areas, for example in Mexico City (e.g., Chaussard et al., 2014) where subsidence zones are increasingly flooded following intense rainstorms.

The Venice region is part of the Po River plain, a foreland region located between the NE-verging northern Apenninic and the SSE-verging eastern South-Alpine chains, which is naturally subsiding (Tosi et al., 2012a, Zecchin and Tosi, 2014). With a surface area of about $550 \mathrm{~km}^{2}$, the Venice Lagoon is the largest Italian wetland open to the Adriatic tides, which are the highest tides of the Mediterranean Sea (Figure 1). The lagoon is connected to the sea through three inlets breaking the narrow littoral strip that separates the inner water body from the Adriatic Sea.

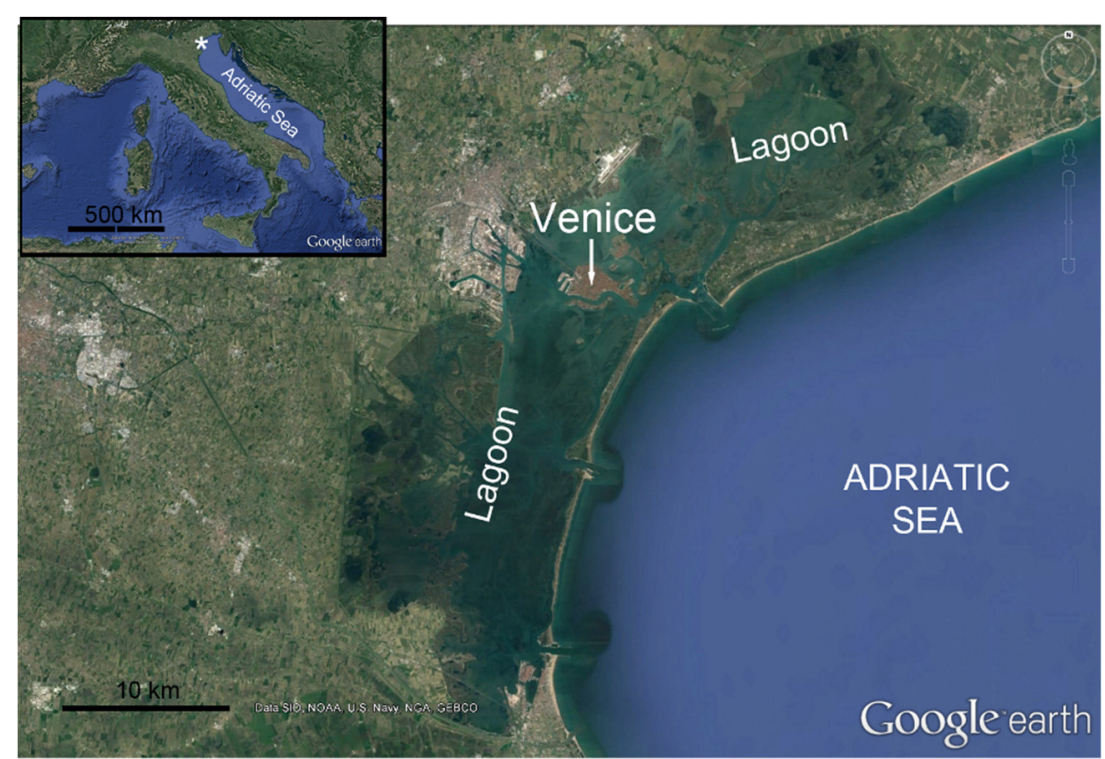

Figure 1. Satellite image of the Venice area (Italy). Source: Google earth.

Venice is one of the most beautiful and famous cities in the world and has coped with floods since its inception, as it developed in a lagoon environment, i.e. on channel levees, salt marshes, and tidal flats. Therefore, the small elevation of the city combined with the regional subsidence of the area and sea-level rise has always been a critical issue for its survival.

On November 4, 1966, an exceptional high tide of $+194 \mathrm{~cm}$ above mean sea level (amsl) affected the city of Venice, with almost the entire historical center flooded by up to $1 \mathrm{~m}$ of sea water (Figure 2). During the following years, this height has never been surpassed. However, the frequency of high tides, i.e. tides above $+110 \mathrm{~cm}$ amsl ("acqua alta" events) flooding more than $12 \%$ of the city center, has continuously increased (Figure 3).

In the aftermath of the 1966 flood, Italy and in the world reacted quickly and emotionally and some immediate physical and economic actions were taken. Among all, the first intervention was the ban of groundwater exploitation, which quickly reduced the sinking rates to the natural values (Teatini et al., 1995 and references therein). The most recent intervention, which is still ongoing, is the construction of the mobile gates (MOSE Project) to close the three lagoon inlets during "acqua alta" events (Tosi et al., 2012b and references therein). In addition, a number of multi-disciplinary studies aimed at understanding and predicting the flooding events as well as investigating the causes responsible for land subsidence and monitoring its occurrence have been systematically carried out. 

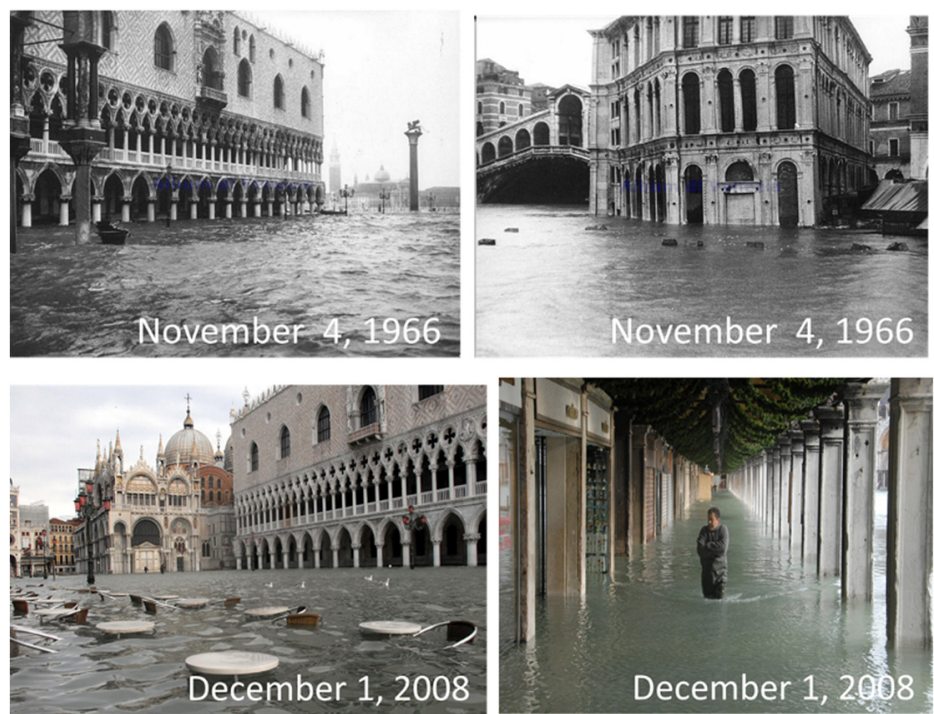

Figure 2. Images of the historical center of Venice during high tides ("acqua alta" events): $+194 \mathrm{~cm}$ amsl in 1966 and $+156 \mathrm{~cm}$ amsl in 2008 .

The retrospective assessments of the subsidence components and the sea-level rise pointed out that, depending on the considered time span, natural subsidence at Venice ranges from 0.6 to $1.6 \mathrm{~mm} / \mathrm{yr}$ and from 0 to $0.5 \mathrm{~mm} / \mathrm{yr}$, over the Holocene and the last century, respectively. Concerning the anthropogenic land subsidence, it was characterized by the largest values during the economic development that followed the Second World War. Because of groundwater withdrawals, a maximum rate of about $1 \mathrm{~cm} / \mathrm{yr}$ was recorded in the late 1960s. This contribution ended in the early 1970, when the wells were closed by law. Recently, ground displacement maps at high spatial resolution obtained by SAR-based Interferometry revealed the occurrence of local displacement velocities in Venice that cannot to be explained by natural processes only. Anthropogenic activities such as restoration works of ancient palaces and other interventions for the maintenance of the historical center likely contribute to a sort of induced subsidence, even if they developed locally and for a short-term period (Tosi et al., 2013).

Although the present subsidence of Venice is not large in magnitude, this process combined with the small ground elevation above the mean sea level and the eustatic rise of the NA has made Venice more prone to flooding. During the past 100 years, sea-level rise and land subsidence of both natural and anthropogenic origin each have accounted for about half $(13 \mathrm{~cm})$ of the cumulative RLS of about $26 \mathrm{~cm}$ (Trincardi et al., 2016) (Figure 3).

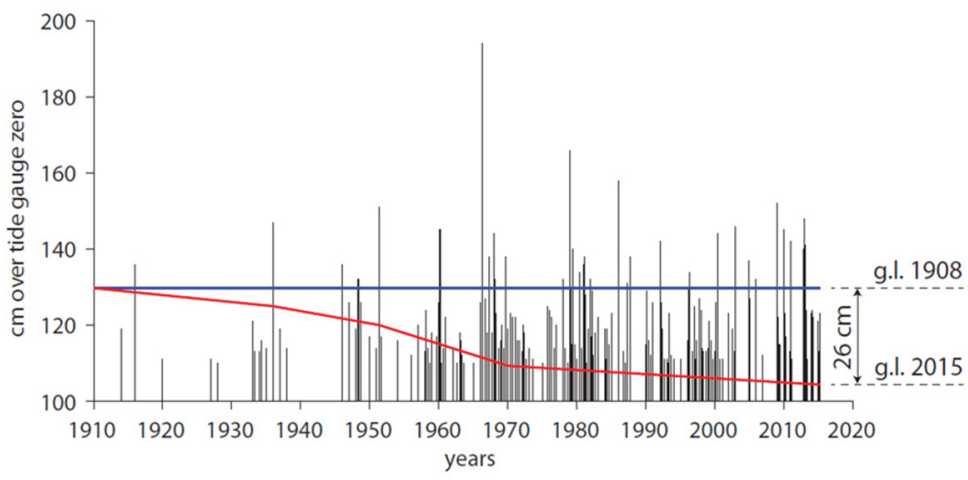

Figure 3. High water events higher than $110 \mathrm{~cm}$ amsl (vertical bars) in Venice since 1910. The blue line represents the ground reference level (g.l.) of 1908 and the red line shows the recorded RSLR. The frequency and intensity of floods has increased over time. An "acqua alta" flood that would have gone unnoticed in 1910 has a significant impact today.

In this work, we provide an updated quantification of the ground elevation lost in Venice over the last 50 years, which depicts the high spatial heterogeneity of the RLS. 
Da Lio et al., Computing the relative land subsidence at Venice, Italy, over the last fifty years

\section{DATA ANALYSIS}

Land movements at Venice have been measured by leveling surveys and SAR-based Interferometry. Leveling was carried out on a network of about 120 benchmarks and five surveys have been considered to calculate the displacement rates for 1961, 1966, 1969, 1973 and 1993. From 1993 to 2016, land movements have been retrieved by the Point Target Analysis (IPTA; Werner et al., 2003; Wegmüller et al., 2004; Teatini et al., 2005), a Persistent Scatterer Interferometry (PSI) technique, with the monitoring networks comprising a few tens of thousands to a hundred thousand point targets. IPTA results have been calibrated (Teatini et al., 2012a, b) using permanent continuous GPS stations (CGPS) well distributed in the frame of the SAR images (larger than the study area), i.e. VEN and VEN1 at Venice, CAVA on the northern Cavallino littoral strip, and SFEL in the nearby of Chioggia at the southern tip of the lagoon (Tosi et al., 2016 and references therein). For the Venice area, the difference between the line-of-sight (LOS) and vertical movements can be considered negligible, assuming the horizontal components of the displacements are negligible (Teatini et al., 2005; Tosi et al., 2010).

The quantification of the land displacement rate $(v)$ over each analyzed period has been obtained interpolating the dataset using the Kriging method on the same regular 50-m grid covering the whole city. The results are mapped in Figure 4.

The trend of the NA sea-level rise has been computed with a linear regression of the yearly values recorded at the tide gauge of Trieste (Figure 5a). Moreover, Figure 5b shows a comparison between the values of $v$ averaged at the city scale with the behavior of the mean sea level averaged over the same periods. Although we are well aware that the latter are not statistically significant due to the too short time intervals, the figure provides a clear summary of the temporal behavior of the two components constituting RLS at Venice.
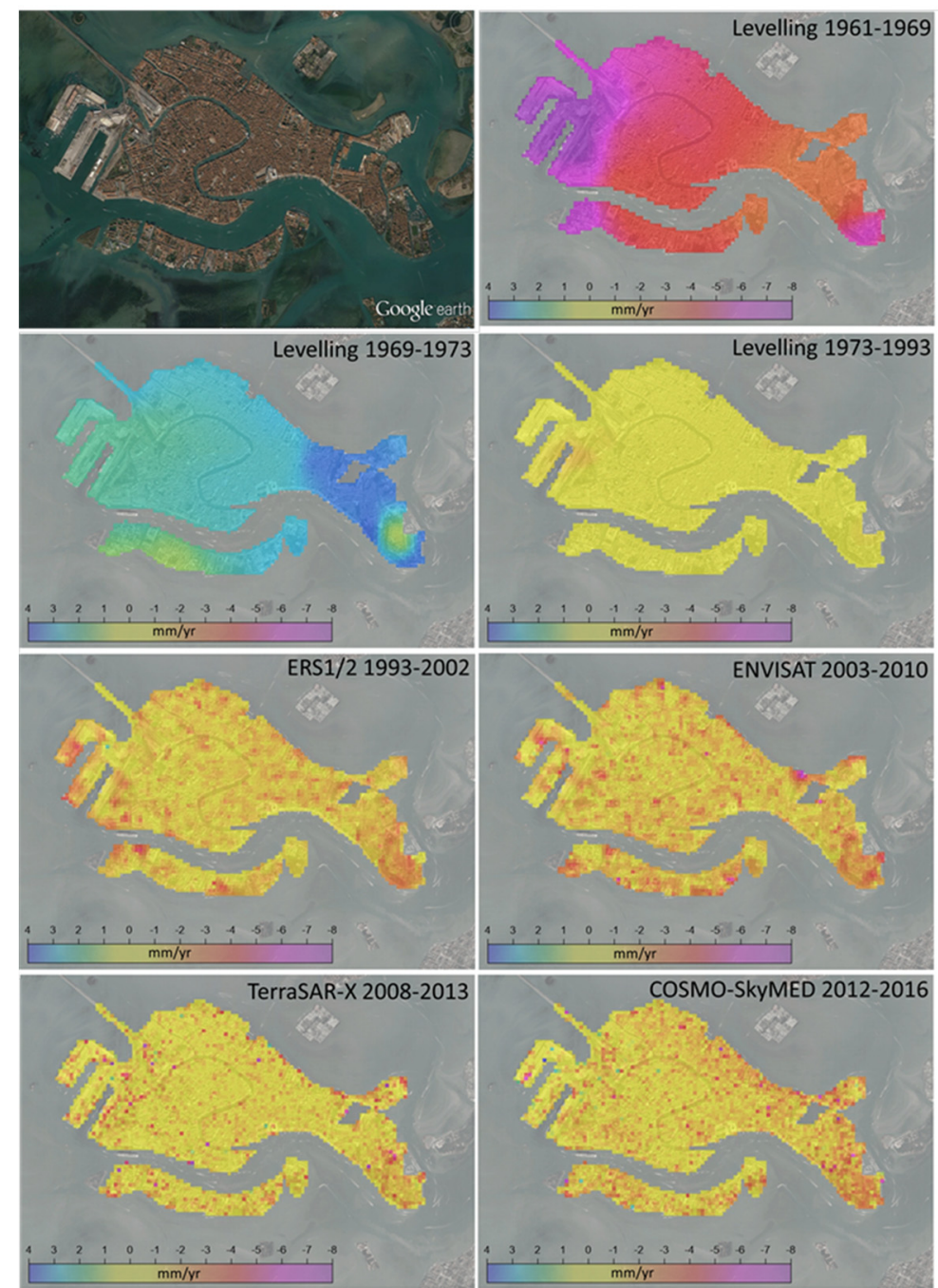

Figure 4. Land velocity $(v)$ at Venice obtained by interpolation of leveling and SAR data in a 50-m regular grid over different time period. Negative values indicate land subsidence. 
Da Lio et al., Computing the relative land subsidence at Venice, Italy, over the last fifty years

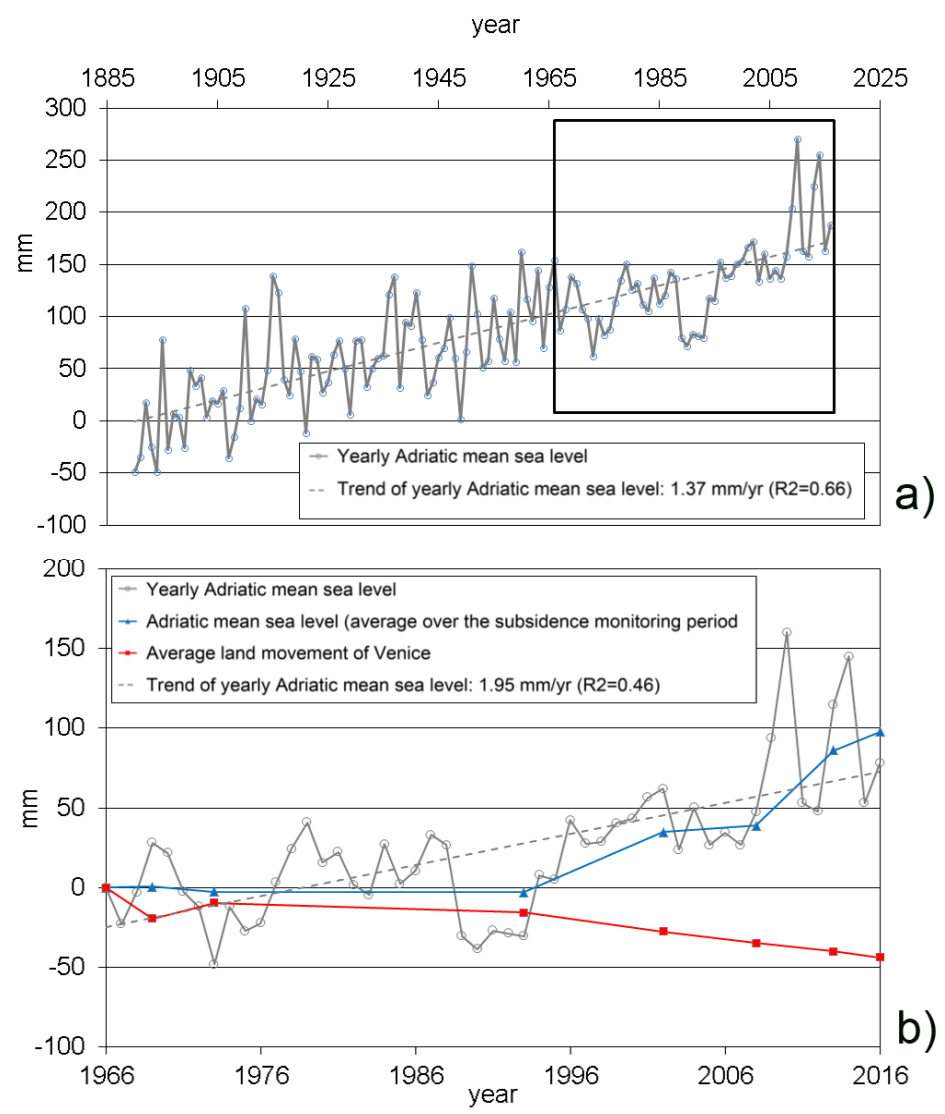

Figure 5. a) Yearly average behavior of the NA sea level at Trieste from 1890 to 2016. The linear trend is also shown. b) Available data from 1966 to 2016 and their simplified analysis: yearly average behavior of the NA sea level at Trieste and its linear trend; average land movement at

Venice (red line) and mean sea level averaged over the same monitoring periods.

\section{MODELLING}

Cumulative land subsidence $\left(L S_{t o t}\right)$ from 1966 to 2016 has been obtained by a GIS processing of the various maps presented in Figure 4 representing the displacement rates over the monitored sub-periods. Specifically, $L S_{\text {tot }}$ is computed as:

$$
\begin{aligned}
& L S_{\text {tot }}=v_{(1961-1969)} \times 4+v_{(1969-1973)} \times 4+v_{(1973-1993)} \times 20+v_{(1993-2002)} \times 9+v_{(2003-2010)} \times \\
& 5+v_{(2008-2013)} \times 5+v_{(2012-2016)} \times 3
\end{aligned}
$$

where the computation has been carried out for each $50 \times 50 \mathrm{~m}$ cell of the grid used to interpolate the original measurements. Notice that each $v_{\text {(time1-time2) }}$ in eq. 1 has been multiplied by the proper number of years to avoid overlapping. For example, $v_{(1961-1969)}$ is multiplied by four years to provide the cumulative subsidence occurred from 1966 to 1969. The modelling outcome is shown in Figure 6a.

Then, the average land subsidence rate $\left(v_{\text {avg }}\right)$ at Venice between 1966 and 2016 is simply derived as follows:

$v_{\text {avg }}=\frac{L S_{t o t}}{50}$

Figure $6 \mathrm{~b}$ shows the result of eq. 2 . The two maps clearly reveal the uneven distribution of the displacements experienced by Venice over the last 50 years. The western and eastern parts of the city, which constitute the most recent portions of the city developed only after 500 years ago, subsided with values up to $90 \mathrm{~mm}$. Contrastingly, much more stability resulted in the central areas with values that, decreasing to less than 0.5 $\mathrm{mm} / \mathrm{yr}$, are representative of the natural subsidence only. Here, sea-level rise is the major component of the RLS experienced at Venice. 


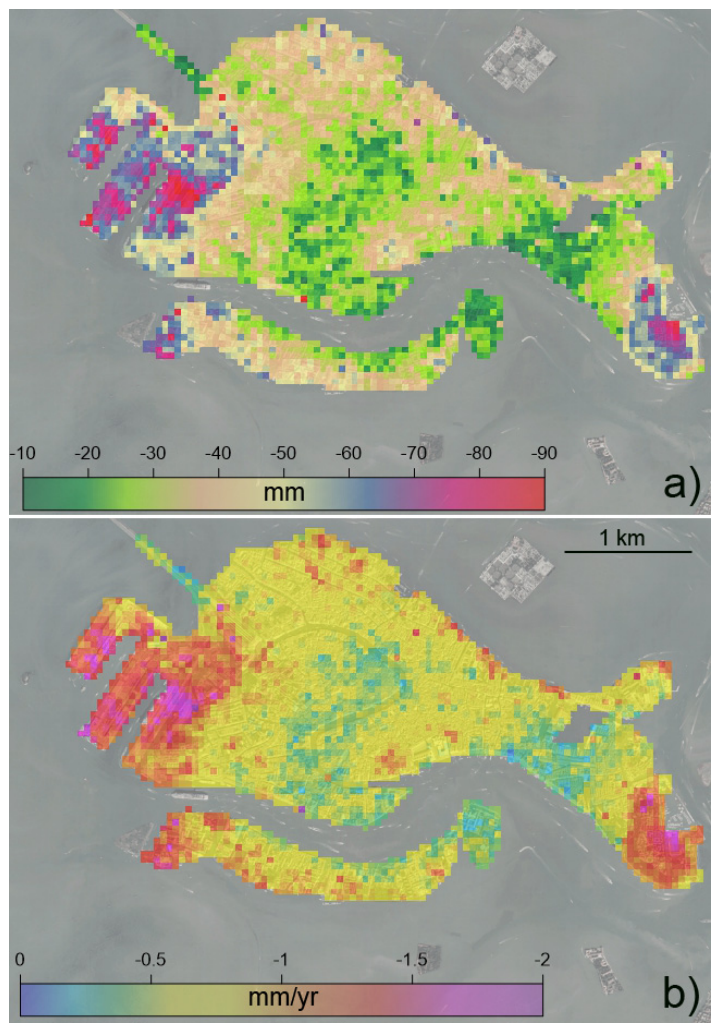

Figure 6. Land subsidence at Venice over the period 1966-2016: a) cumulative land subsidence obtained by eq. 1 ; b) average land velocity $\left(v_{\text {avg }}\right)$ obtained by eq. 2 .

\section{CONCLUSIONS}

An innovative approach has been developed to model the cumulative land subsidence and the vertical displacement velocity over the last 50 years after the terrible event of the highest tide occurred in Venice on 1966.

Ground displacements have been computed by GIS processing of leveling surveys and IPTA with the component of sea-level rise obtained by the analysis of tide gauge records.

The results point out that in the Venice historical center between 1966 and 2016:

- Land subsidence rate has been more variable in space but less variable over time than the changes of the NA mean sea level;

- average subsidence has amounted to $0.8 \mathrm{~mm} / \mathrm{yr}$ and the average NA msl rise to $1.9 \mathrm{~mm} / \mathrm{yr}$;

- minimum and maximum cumulative subsidence has totalled $8 \mathrm{~mm}$ and $93 \mathrm{~mm}$, respectively; and

- maximum loss of elevation with respect to the NA msl (i.e. RLS) has been $190 \mathrm{~mm}$.

RLS has produced a tangible effect on the Venice historical center revealed by the continuous increase in frequency of the flooding events, locally called "acqua alta". In the next years, any further loss of elevation with respect to the mean sea level, even few $\mathrm{mm}$, will threat the city survival with severe social and environmental impacts, also in relation to the expected global climate change. The outcomes from this study should be properly taken in account for the planning of effective interventions for the mitigation of climate changes to maintain the historical center of this unique city.

\section{ACKNOWLEDGMENTS}

This work has been developed in the framework of the Flagship Project RITMARE - The Italian Research for the Sea - coordinated by the Italian National Research Council and funded by the Italian Ministry of Education, University and Research within the National Research Program 2011-2013. Data courtesy: (1) TerraSAR-X, Project COA0612 (C) DLR “Assessing vertical movements of natural tidal landforms and anthropogenic structures at the Venice Lagoon inlets"; (2) COA1800CDLR "Ground surface dynamics in the Venice Lagoon: five years of monitoring of natural tidal landforms and anthropogenic structures by 
Da Lio et al., Computing the relative land subsidence at Venice, Italy, over the last fifty years

TerraSAR-X"; (3) RADARSAT-2 and COSMO-SkyMed, Project 2940CASI and 5266CSOAR (COSMOSkyMed/RADARSAT-2 initiative); (4) ERS data: Project VENEZIA: Subsidence monitoring service in the lagoon of Venice for regional administrative and water authorities, DUP (C ESA; ENVISAT ASAR data, Project INLET, Venice Water Authority - ISMAR, CNR. We thank Devin L. Galloway (U.S. Geological Survey) and Shujun Ye (Nanjing University, P.R. China) for their careful reading of our manuscript and their many insightful comments and suggestions.

\section{REFERENCES}

Chaussard, E., Wdowinski, S., Cabral-Cano, E., and Amelung, F. (2014). Land subsidence in central Mexico detected by ALOS InSAR time-series. Remote Sensing of Environment, 140: 94-106.

Ng, A. H.-M., Ge, L., Li, X., Abidin, H. Z., Andreas, H., and Zhang K. (2012). Mapping land subsidence in Jakarta, Indonesia using persistent scatterer interferometry (PSI) technique with ALOS PALSAR. International Journal of Applied Earth Observation and Geoinformation, 18, 232-242.

Strozzi, T., Teatini, P., and Tosi, L. (2009). TerraSAR-X reveals the impact of the mobile barrier works on Venice coastland stability. Remote Sensing of Environment, 113(12), 2682-2688.

Teatini, P., Gambolati, G., and Tosi, L. A new 3-D non-linear model of the subsidence of Venice. In Land Subsidence; Barends, F.B.J., Ed.; IAHS Publishing: Wallingford, UK, 1995; pp. 353-361.

Teatini, P., Tosi, L., Strozzi, T., Carbognin, L., Wegmüller, U., and Rizzetto, F. (2005). Mapping regional land displacements in the Venice coastland by an integrated monitoring system. Remote Sensing of Environment, 98, 403-413.

Teatini, P., Tosi, L., Strozzi, T., Carbognin, L., Cecconi, G., Rosselli, R., and Libardo, S. (2012a). Resolving land subsidence within the Venice Lagoon by persistent scatterer SAR interferometry. Physics and Chemistry of the Earth, Parts $A / B / C, 40,72-79$.

Teatini, P., Tosi, L., and Strozzi, T. (2012b). Comment on "Recent subsidence of the Venice Lagoon from continuous GPS and interferometric synthetic aperture radar' by Y. Bock, S. Wdowinski, A. Ferretti, F. Novali, and A. Fumagalli. Geochemistry, Geophysics, Geosystems 13, Q07008, doi:10.1029/2012GC004191.

Tosi, L., Da Lio, C., Strozzi, T., and Teatini, P. (2016). Combining L- and X-Band SAR Interferometry to Assess Ground Displacements in Heterogeneous Coastal Environments: The Po River Delta and Venice Lagoon, Italy. Remote Sensing, 8, doi: 10.3390/rs8040308.

Tosi, L., Teatini, P., Strozzi, T., Carbognin, L., Brancolini, G., and Rizzetto, F. (2010). Ground surface dynamics in the northern Adriatic coastland over the last two decades. Rendiconti Lincei. Scienze Fisiche e Naturali, 21, S115-S129.

Tosi, L., Teatini, P., Brancolini, G., Zecchin, M., Carbognin, L., Affatato, A., and Baradello, L. (2012a). Three-dimensional analysis of the Plio-Pleistocene seismic sequences in the Venice Lagoon (Italy). Journal of the Geological Society, 169, 507-510, doi: 10.1144/0016-76492011-093.

Tosi, L., Teatini, P., Bincoletto, L., Simonini, P., and Strozzi, T. (2012b). Integrating geotechnical and interferometric SAR measurements for secondary compressibility characterization of coastal soils. Survey in Geophysics, 33 (5), 907-926.

Tosi, L., Teatini, P., and Strozzi, T. (2013). Natural versus anthropogenic subsidence of Venice. Scientific Reports, 3:2710, doi:10.1038/srep02710.

Trincardi. F, Barbanti, A., Bastianini, M., Benetazzo, A., Cavaleri, L., Chiggiato, J., Papa, A., Pomaro, A., Sclavo, M., Tosi, L., and Umgiesser, G. (2016). The 1966 Flooding of Venice: What Time Taught Us for the Future. Oceanography, 29, 178-186, doi: 10.5670/oceanog.2016.87.

Wegmüller, U., Werner, C., Strozzi, T., and Wiesmann, A. (2004): Multitemporal interferometric point target analysis. Ser. Remote Sens. 3, 136-144.

Werner, C., Wegmüller, U., Strozzi, T., and Wiesmann, A. (2003). Interferometric Point Target Analysis for deformation mapping. Proc. of the Geoscience and Remote Sensing Symposium (IGARSS 2003), IEEE International 7, 4362-4364.

Zecchin, M., and Tosi, L. (2014). Multi-sourced depositional sequences in the Neogene to Quaternary succession of the Venice area (northern Italy). Marine and Petroleum Geology, 56, 1-15. 